\title{
Assesment Neuropatic Sensoric (ANES) Model untuk Mencegah Ulkus Diabetik Penderita DM Type II di Desa Menganti Kecamatan Kesugihan Cilacap
}

\author{
Suko Pranowo ${ }^{1}$, Ida Ariani ${ }^{2}$, Dwi Setiyawati ${ }^{3}$ \\ ${ }^{1}$ Prodi D3 Keperawatan, ${ }^{2}$ Prodi Ners, ${ }^{3}$ Prodi D3 Fisioterapi \\ STIKES Al-Irsyad Al-Islamiyyah, Jalan Cerme No 24 Sidanegara Cilacap 53223 \\ Email korespondensi: supra74sukopranowo@gmail.com
}

\begin{abstract}
Abstrak
Sebanyak 1785 penderita DM di Indonesia yang mengalami komplikasi 63,5\% mengalami neuropati dan dari penderita DM sekitar 15\% mengalami uklus kaki. Gangguan kaki pada penderita DM akibat adanya ulkus, gangren, infeksi bahkan amputasi dapat menyebabkan perubahan aktivitas, kesakitan, mempengaruhi lamanya seseorang di rawat inap, dan biaya yang dikeluarkan lebih besar. Pencegahan terjadinya ulkus pada penderita DM sangat penting dilakukan yaitu dengan pengkajian kaki melalui anamnese dan pemeriksaan. Pengabdian kepada masyarakat ini dilakukan di Desa Menganti, dimana kader dan penderita DM belum mengetahui tentang cara melakukan pencegahan dan pemeriksaan ulkus kaki. Tim memberikan pemahaman kepada penderita DM tentang Assessment Neuropaty Sensoric (ANES) atau pengkajian neuropati sensorik sebagai upaya deteksi dini mencegah terjadinya ulkus diabetik. Diharapkan penderita DM Type II dapat memahami dan melakukan praktik pemeriksaan neuropati sensorik sehingga terhindar dari kejadian ulkus diabetik. Metode kegiatan dilakukan bertahap; 1) Meningkatkan pengetahuan tentang ulkus kaki. 2) Meningkatkan keterampilan penderita DM, 3) Simulasi praktek, dan 4) Evaluasi hasil praktik. Hasil kegiatan ini adalah terjadi peningkatan pengetahuan yang signifikan yaitu kategori baik sebelum intervensi pendidikan kesehatan sebanyak 4 orang $(14,81 \%)$ dan kategori baik setelah dilakukan intervensi pendidikan kesehatan sebanyak 22 orang $(81,48 \%)$. Terdapat kenaikan jumlah responden yang memiliki kategori baik setelah diberikan pendidikan kesehatan yaitu 24 orang $(88,89 \%)$, terdapat peningkatan rata-rata nilai keterampilan dari 0 menjadi 87,41. Diharapkan bagi penderita agar melakukan pemeriksaan dini antar penderita dalam upaya pencegahan terjadinya ulkus diabetik.
\end{abstract}

Keywords: Pengkajian Sensori Neuropati, ulkus kaki.

\begin{abstract}
A total of 1785 DM sufferers in Indonesia who experienced complications $63.5 \%$ experienced neuropathy and about 15\% of DM sufferers experienced leg size. Foot disorders in people with DM due to ulcers, gangrene, infections and even amputations can cause changes in activity, pain, affect the length of time someone is hospitalized, and the costs incurred are greater. Prevention of ulcers in patients with DM is very important to do with the assessment of the foot through anamnes and examination. Service to the community is done in the village of Menganti, where cadres and DM sufferers do not know about how to prevent and examine foot ulcers. provide DM sufferers with an understanding of the Sensory Neuropathy Assessment (ANES) or the assessment of sensory neuropathy as an early detection effort to prevent diabetic ulcers. It is expected that people with Type II DM can understand and practice the practice of sensory neuropathy so as to avoid the incidence of diabetic ulcers. The method of activity is carried out in stages; 1) Increase knowledge about foot ulcers. 2) Improve the skills of people with DM, 3) Practice simulations, and 4) Evaluate practice results. The results of this activity are a significant increase in knowledge
\end{abstract}


namely the good category before health education interventions of 4 people (14.81\%) and the good category after health education interventions of 22 people (81.48\%). There was an increase in the number of respondents who had a good category after being given health education namely 24 people ( $88.89 \%$ ), there was an increase in the average value of skills from 0 to 87.41. It is expected for sufferers to carry out early examinations between patients in an effort to prevent the occurrence of diabetic ulcers.

Keywords: Assesment Neuropaty Sensoric, foot ulcer.

\section{PENDAHULUAN}

Diabetes melitus adalah sekelompok kelainan heterogen yang ditandai oleh kenaikan kadar glukosa dalam darah atau hiperglikemia (Smeltzer \& Bare, 2010). Diabetes melitus merupakan masalah kesehatan global yang insidensinya semakin meningkat. Sebanyak 346 juta orang di dunia menderita diabetes, dan diperkirakan mencapai 380 juta jiwa pada tahun 2025 (WHO, 2011).

Indonesia kini telah menduduki rangking keempat jumlah penyandang diabetes terbanyak setelah Amerika Serikat, China dan India. Berdasarkan data dari Badan Pusat Statistik (BPS) jumlah penyandang diabetes pada tahun 2003 sebanyak 13,7 juta orang dan berdasarkan pola pertambahan penduduk diperkirakan pada 2030 akan ada 20,1 juta penyandang diabetes dengan tingkat prevalensi 14,7 persen untuk daerah urban dan 7,2 persen di rural. Organisasi Kesehatan Dunia (WHO) memprediksi kenaikan jumlah penyandang diabetes mellitus di Indonesia dari 8,4 juta pada tahun 2000 menjadi sekitar 21,3 juta pada tahun 2030. Sedangkan Badan Federasi Diabetes Internasional (IDF) pada tahun 2009 memperkirakan kenaikan jumlah penyandang diabetes mellitus dari 7,0 juta tahun 2009 menjadi 12,0 juta pada tahun 2030. (PERKENI, 2011)

Menurut RISKESDAS tahun 2013 menyebutkan terjadi peningkatan prevalensi pada penderita diabetes melitus yang diperoleh berdasarkan wawancara yaitu 1,1\% pada tahun 2007 menjadi 1,5\% pada tahun 2013 sedangkan prevalensi diabetes melitus berdasarkan diagnosis dokter atau gejala pada tahun 2013 sebesar 2,1\% dengan prevalensi terdiagnosis dokter tertinggi pada daerah Sulawesi Tengah $(3,7 \%)$ dan paling rendah pada daerah Jawa Barat $(0,5 \%)$. Prevalensi dari penderita DM cenderung meningkat pada perempuan dibandingkan dengan laki-laki dan terjadi peningkatan prevalensi penyakit diabetes melitus sesuai dengan pertambahan umur namun mulai umur $\geq 65$ tahun cenderung menurun dan tersebut cenderung lebih tinggi bagi penderita yang tinggal diperkotaan dibandingkan 
dengan dipedesaan. Jika ditinjau dari segi pendidikan menurut RISKESDAS bahwa prevalensi diabetes melitus cenderung lebih tinggi pada masyarakat dengan tingkat pendidikan tinggi serta dengan kuintil indeks kepemilikan yang tinggi (RISKESDAS, 2013).

Komplikasi yang dapat terjadi pada penderita DM yaitu ; komplikasi akut (ketoasidosis diabetik, status hiperglikemia hiperosmolar, dan hipoglikemia). Komplikasi kronis yang menahun dapat dibagi menjadi makroangiopati, mikroangiopati dan neuropati. Komplikasi makroangiopati meliputi kelainan kardiovaskuler, kelainan serebrovaskuler, dan kelainan pembuluh darah tepi. Komplikasi mikroangiopati meliputi retinopati dan nefropati (PERKENI, 2011). Komplikasi tersebut menyebabkan penderita DM tidak dapat menjadi seorang yang produktif sehingga beban ekonomi keluarga akan meningkat hingga kematiannya.

Sebanyak 1785 penderita DM di Indonesia yang mengalami komplikasi: 16\% penderita DM mengalami komplikasi makrovaskuler, 27,6\% komplikasi mikrovaskuler, 63,5\% mengalami neuropati, 42\% retinopati diabetes, dan 7,3\% nefropati (Soewondo dkk, 2010). Angka kejadian ulkus kaki sekitar 15\% dari penderita DM. Walaupun angka kejadian kecil terjadi gangguan pada kaki, akan tetapi mempunyai dampak besar (Heitzman, 2010). Gangguan kaki pada penderita DM akibat adanya ulkus, gangren, infeksi bahkan amputasi. Gangguan kaki ini dapat terjadi perubahan aktivitas, menyebabkan kesakitan, mempengaruhi lamanya seseorang di rawat inap, dan biaya yang dikeluarkan lebih besar pada penderita DM.

Risiko infeksi dan amputasi masih cukup tinggi, yaitu 40-80\% ulkus kaki diabetik mengalami infeksi (Bernard, 2007), 14-20\% memerlukan amputasi (Frykberg dkk., 2000), 66\% mengalami kekambuhan dan 12\% memiliki risiko amputasi dalam 5 tahun setelah sembuh. Kebanyakan pasien datang berobat dalam fase lanjut, terlihat dari proporsi ulkus kaki diabetik Wagner III-V mencapai 74,6 $\%$ dibandingkan dengan Wagner I-II yang hanya mencapai 25,4\% dari seluruh kasus ulkus kaki diabetik yang dirawat di RS Sanglah, dengan kecendrungan semakin tinggi derajat ulkus semakin besar risiko amputasi (Muliawan dkk., 2007). Keadaan ini sangat berkaitan dengan keterlambatan diagnosis dan konsultasi, penanganan yang tidak adekuat, serta luasnya kerusakan jaringan (Van Baal, 2004). 
Penelitian yang dilakukan oleh Purwanti (2013) tentang Hubungan Faktor Risiko Neuropati dengan Kejadian Ulkus Kaki pada Pasien Diabetes Mellitus di RSUD Moewardi Surakarta, menunjukkan bahwa responden yang terjadi ulkus sebanyak 85,3\% mengalami neuropati sensorik, dan terdapat hubungan antara neuropati sensorik dengan kejadian ulkus. Hasil nilai OR: 6,525, hal ini dapat diartikan pasien yang mengalami neuropati sensorik memiliki kemungkinan 6,525 kali terjadi ulkus dibandingkan pasien yang tidak mengalami neuropati sensorik. Pada sel scwann dan neuron terjadi penumpukan sorbitol yang dapat mengurangi hantaran saraf,sehingga dapat mempengaruhi saraf sensorik yang dapat memunculkan polineuropati (Silbernagl and Lang, 2007). Neuropati perifer merupakan polineuropati terdiri dari neuropati sensori, neuropati motorik, neuropati otonom (Heitzman, 2010). Sekitar 45-60 \% semua penderita ulkus diabetik murni karena neuropati, sedangkan $45 \%$ akibat neuropati dan iskemia (Frygberk, et al., 2006).

Untuk itu, perlu mencegah terjadi ulkus pada penderita DM. Salah satu cara mencegah terjadi ulkus, dengan cara pengkajian kaki melalui anamnese dan pemeriksaan. Pengkajian ini dapat menentukan penyebab dan faktor risiko ulkus kaki DM. Sangat penting dan utama dalam hal menentukan faktor risiko terjadi ulkus. Hal ini merupakan strategi pencegahan ulkus, dan perawat memiliki peran (Delmas, 2006). Peran perawat untuk mengidentifikasi faktor risiko, menghindari ulkus berulang, dan mencegah terjadinya amputasi pada penderita DM. Untuk itu, perlunya perawat menggali riwayat pasien, melakukan pemeriksaan fisik atau tes diagnostik yang sesuai (Registered Nurses’ Association of Ontario, 2011.)

Pengabdian kepada masyarakat ini dilakukan di Desa Menganti Kecamatan Kesugihan. Tujuan dari pengabdian kepada masyarakat ini adalah memberikan pemahaman kepada penderita DM tentang pengkajian neuropati sensorik sebagai upaya deteksi dini mencegah terjadinya ulkus diabetik. Diharapkan penderita DM Type II dapat memahami dan melakukan praktik pemeriksaan neuropati sensorik sehingga terhindar dari kejadian ulkus diabetik. 


\section{MASALAH}

Berdasarkan hasil observasi di lapangan oleh tim pengusul melalui wawancara dengan Kepala Desa dan kader Desa Menganti didapatkan bahwa 2 orang yang dirawat di RSUD Cilacap karena terdapat luka/ulkus di kaki, 1 orang diantaranya sudah diamputasi. Keterlambatan penderita mengetahui adanya rasa kebas pada kaki merupakan faktor risiko utama terjadinya luka. Permasalahan yang terjadi di Desa Menganti adalah masih rendahnya pengetahuan penderita DM Type II tentang pengkajian neuropatik sensorik untuk mencegah ulkus diabetic dan masih rendahnya keterampilan penderita DM Type II tentang pengkajian neuropatik sensorik untuk mencegah ulkus diabetik.

\section{METODE PELAKSANAAN}

Pengabdian kepada masyarakat ini dilaksanakan di Desa Menganti. Sasaran pelaksanaan kegiatan adalah seluruh kader dan seluruh penderita DM Desa Menganti.

Berdasarkan identifikasi masalah yang telah dirumuskan, maka kami menawarkan solusi permasalahan melalui serangkaian kegiatan dengan melibatkan partisipasi aktif dari penderita DM Type II dan Kader Desa Menganti sebagai berikut :

1) Persiapan

a. Melakukan koordinasi dengan pihak Puskesmas Kesugihan meliputi pendataan, penetapan peserta.

b. Melakukan koordinasi dengan aparat Desa Menganti untuk pemilihan daerah yang akan dijadikan tempat pengabdian masyarakat.

c. Kriteria peserta adalah penderita DM Type II dan Kader, bersedia ikuti pelatihan, memiliki waktu yang cukup dan berpartisipasi aktif dalam kegiatan kelompok

d. Tahap persiapan dilakukan 2 hari

2) Pelaksanaan Pelatihan

Pengabdian dilaksanakan pada tanggal 12 April 2018 kepada masyarakat di Desa Menganti sebanyak 27 orang. 
Metode pelaksanaannya adalah sebagai berikut:

a. Pre test

Pada sesi ini dilakukan test untuk mengetahui sejauh mana pengetahuan tentang pemeriksaan neuropati sensorik. Pre test dilakukan 15 menit.

b. Pemberian materi

Materi meliputi konsep dasar DM, pemeriksaan neuropati sensorik dan praktik pemeriksaan neuropati sensori. Metode yang digunakan yaitu ceramah menggunakan media LCD, Laptop, Modul, dan praktik tentang pemeriksaan neuropati sensorik menggunakan alat monofilament. Materi diberikan selama 60 menit, dan diberikan oleh 3 pembicara secara bergantian. Pembicara 1 tentang konsep DM, Pembicara 2 tentang konsep Ulkus DM dan Pembicara 3 tentang Pemeriksaan ANES.

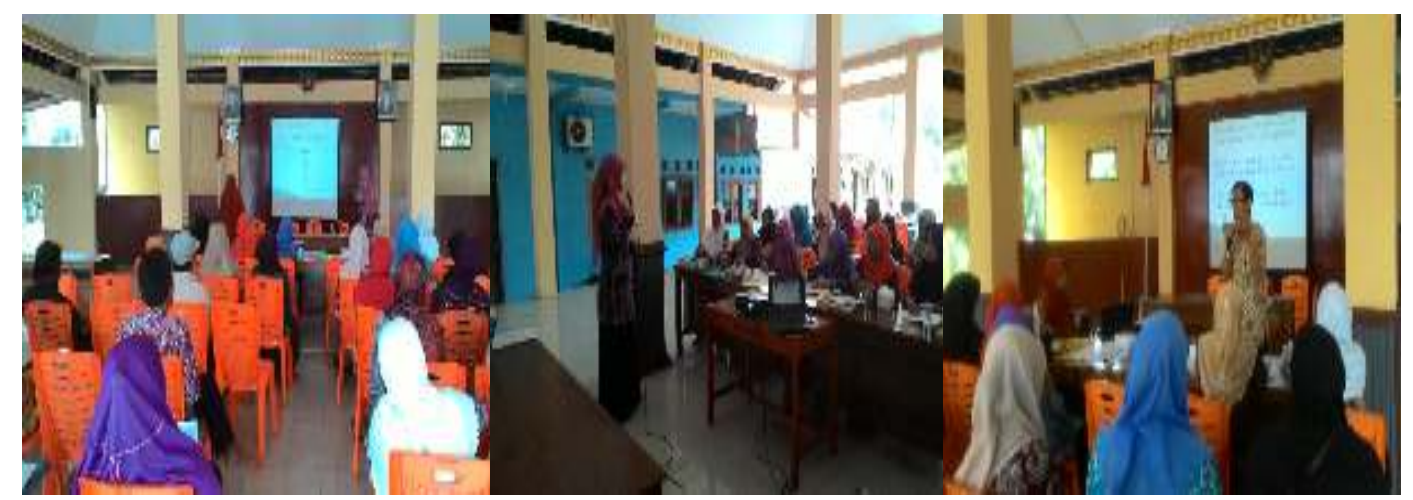

Gambar 1. Proses Pemberian Materi

c. Post test

Tahap ini merupakan sesi untuk mengukur sejauh mana pengetahuan dan keterampilan tentang pemeriksaan neuropati sensorik.

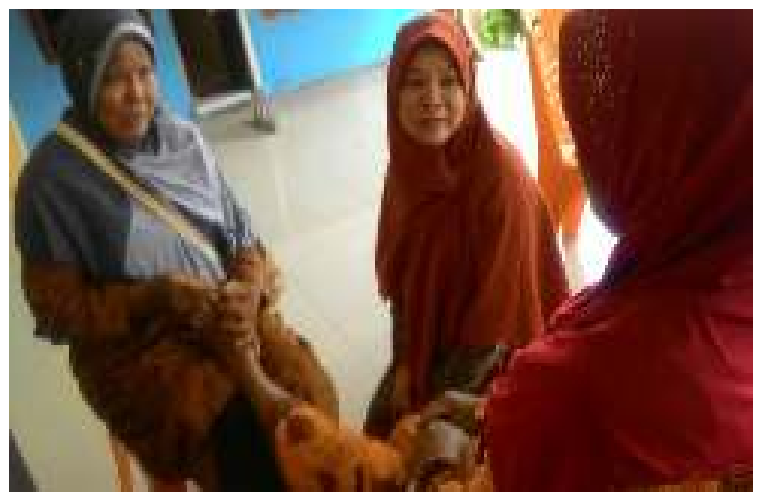

Gambar 2. Saat Dilakukan Post Test

Jurnal Pengabdian Masyarakat Al-Irsyad Vol. II, No. 1. April 2020 
d. Tahap pelaksanaan dilakukan 1 hari.

3) Monitoring dan evaluasi

Tahap ini dilakukan oleh tim pelaksana pengabdian. Tujuan dilakukan monitoring dan evaluasi adalah untuk memastikan bahwa mereka melakukan pemeriksaan secara rutin dan mengajarkan kepada penderita lain yang tidak mengikuti kegiatan ini. Tahap ini dilakukan 2 kali dalam 1 bulan dengan melakukan kunjungan penderita pada minggu pertama dan ketiga.

\section{HASIL DAN PEMBAHASAN}

Hasil kegiatan pengabdian pada kader dan penderita DM di Desa Menganti sebagai berikut:

\section{1) Hasil}

Adapun hasil penilaian kuesioner pretest dan pos test terhadap pengetahuan dan keterampilan masyarakat tentang pencegahan ulkus diabetik adalah sebagai berikut:

a. Pre Test

Tabel 1

Distribusi Frekuensi Pengetahuan Masyarakat Sebelum Diberikan Pendidikan Kesehatan Tentang Pencegahan Ulkus Diabetik Di Desa Menganti Kecamatan Kesugihan

\begin{tabular}{llll}
\hline No. & Ketrampilan & Frekuensi & Persen \\
\hline 1 & Baik & 4 & 14,81 \\
2 & Cukup & 11 & 40,74 \\
3 & Kurang & 12 & 44,44 \\
\hline Jumlah & 27 & 100 \\
\hline Rata-rata Nilai $=60,74$ & &
\end{tabular}

Sumber : Data Primer tahun 2018

Berdasarkan tabel 1 dapat diketahui bahwa responden sebelum diberikan pendidikan kesehatan tentang pencegahan ulkus diabetik paling banyak mempunyai pengetahuan dengan kategori kurang baik yaitu 12 orang $(44,44 \%)$, paling sedikit mempunyai pengetahuan dengan kategori baik sebanyak 4 orang (14,81\%). Memiliki rata-rata nilai pengetahuan 60,74. 
Tabel 2

Distribusi Frekuensi Keterampilan Masyarakat Sebelum

Diberikan Pendidikan Kesehatan Tentang Pencegahan Ulkus Diabetik

Di Desa Menganti Kecamatan Kesugihan

\begin{tabular}{llll}
\hline No. & Ketrampilan & Frekuensi & Persen \\
\hline 1 & Baik & 0 & 0 \\
2 & Cukup Baik & 0 & 0 \\
3 & Kurang Baik & 0 & 0 \\
$4 \quad$ Tidak Baik & 27 & 100 \\
\hline Jumlah & 27 & 100 \\
\hline Rata-rata Nilai $=0$ & &
\end{tabular}

Berdasarkan tabel 2 dapat diketahui bahwa responden sebelum diberikan pendidikan kesehatan tentang pencegahan ulkus diabetik semua mempunyai keterampilan dengan kategori tidak baik yaitu 27 orang $(100 \%)$, dengan rata-rata nilai keterampilan 0 .

b. Post Test

Tabel 3

Distribusi Frekuensi Pengetahuan Masyarakat Setelah

Diberikan Pendidikan Kesehatan Tentang Pencegahan Ulkus Diabetik Di Desa Menganti Kecamatan Kesugihan

\begin{tabular}{llll}
\hline No. & Ketrampilan & Frekuensi & Persen \\
\hline 1 & Baik & 22 & 81,48 \\
2 & Cukup & 5 & 18,52 \\
$3 \quad$ Kurang & 0 & 0 \\
\hline Jumlah & 27 & 100 \\
\hline Rata-rata Nilai $=83,70$ & &
\end{tabular}

Berdasarkan tabel 3 dapat diketahui bahwa setelah responden diberikan pendidikan kesehatan tentang pencegahan ulkus diabetik paling banyak mempunyai pengetahuan dengan kategori baik yaitu 22 orang $(81,48 \%)$ dan paling sedikit mempunyai pengetahuan dengan kategori cukup baik sebanyak 5 orang $(18,52 \%)$. Responden memiliki rata-rata nilai pengetahuan 83,70.

Tabel 4

Distribusi Frekuensi Keterampilan Masyarakat Setelah Diberikan Pendidikan Kesehatan Tentang Pencegahan Ulkus Diabetik Di Desa Menganti Kecamatan Kesugihan

\begin{tabular}{llll}
\hline No. & Ketrampilan & Frekuensi & Persen \\
\hline 1 & Baik & 24 & 88,89 \\
2 & Cukup & 3 & 11,11 \\
3 & Kurang & 0 & 0 \\
\hline Jumlah & 27 & 100 \\
\hline Rata-rata Nilai $=87,41$ & &
\end{tabular}


Berdasarkan tabel 4 dapat diketahui bahwa setelah diberikan pendidikan kesehatan tentang pencegahan ulkus diabetik sebagian besar mempunyai keterampilan dengan kategori baik yaitu 24 orang (100\%) dan paling sedikit memiliki keterampilan dengan kategori cukup baik yaitu 3 orang (\%), dengan ratarata nilai keterampilan 87,41 .

Tabel 5 Hasil Uji Wilcoxon's Rank Test

\begin{tabular}{lc}
\hline \multicolumn{1}{c}{ Variabel } & p Value \\
\hline Pengetahuan Sebelum dan Setelah dilakukan pendidikan Kesehatan & 0.0005 \\
\hline Sumber : Data Primer tahun 2018 &
\end{tabular}

Berdasarkan tabel 5 dapat diketahui bahwa terdapat pengaruh yang signifikan pemberian pendidikan kesehatan tentang ANES terhadap peningkatan pengetahuan $(\mathrm{pv}=0,0005)$.

\section{2) Pembahasan}

Dari hasil pelaksanaan pengabdian didapatkan data bahwa terjadi peningkatan pengetahuan yang signifikan yaitu kategori baik sebelum intervensi pendidikan kesehatan sebanyak 4 orang $(14,81 \%)$ dan kategori baik setelah dilakukan intervensi pendidikan kesehatan sebanyak 22 orang $(81,48 \%)$. Terdapat kenaikan jumlah responden yang memiliki pengetahuan dengan kategori baik yaitu sebanyak 18 orang. Memiliki selisih rata-rata pre dan post test nilai pengetahuan sebanyak 22,96. Terdapat kenaikan jumlah responden yang memiliki kategori baik setelah diberikan pendidikan kesehatan yaitu 24 orang $(88,89 \%)$, terdapat peningkatan ratarata nilai keterampilan dari 0 menjadi 87,41.

Kurangnya pengetahuan wanita tentang pencegahan ulkus diabetik dengan pemeriksaan ANES, dapat menyebabkan seseorang kurang memperhatikan terhadap kemungkinan adanya penurunan sensasi yang dapat berkembang menjadi ulkus diabetik. Dengan demikian tidak muncul suatu respon dalam bentuk sikap yang mendukung dilakukannya pemeriksaan ANES. Tidak munculnya sikap yang mendukung terhadap pemeriksaan ANES, akhirnya tidak melakukan pemeriksaan sehingga tidak ada upaya pencegahan terhadap ulkus diabetik.

Menurut Nasution (2004) menjelaskan pendidikan kesehatan merupakan salah satu faktor untuk meningkatkan perilaku kesehatan yang baik. Hasil penelitian menunjukkan terdapat kategori kurang sebelum dilakukan pendidikan kesehatan. Hal ini dimungkinkan karena pengetahuan tentang Pencegahan Ulkus dengan 
Pemeriksaan ANES sebelumnya belum pernah diberikan oleh tim pengabdian yang lain. Pengetahuan menjadi baik jika seseorang mendapatkan informasi, dimana informasi bisa didapatkan dengan pendidikan kesehatan

Pendidikan kesehatan merupakan suatu kegiatan atau usaha untuk menyampaikan informasi kesehatan kepada individu, kelompok ataupun masyarakat, sehingga dapat memperoleh pengetahuan kesehatan yang lebih baik dan dapat berpengaruh terhadap perilakunya (Notoatmodjo, 2010).

\section{KESIMPULAN}

Kesimpulan kegiatan pengabdian ini adalah:

1) Terjadi peningkatan pengetahuan penderita DM Type II tentang pengkajian neuropatik sensorik untuk mencegah ulkus diabetik.

2) Terjadi peningkatan keterampilan penderita DM Type II tentang pengkajian neuropatik sensorik untuk mencegah ulkus diabetik.

\section{DAFTAR PUSTAKA}

Bernard, L. (Chairman Working Group). (2007). Clinical practice guidelines: Management of diabetic foot infections. Medicine et maladies infectieuses, $37: 14-25$.

Delmas, L. (2006). Best Practice in the Assesmentand Management of Diabetic Foot ulcers. Rehabilitation Nursing. 31. 6. November/December

Frygberk, R. G., Armstrong, D.G., Driver, V.R,Gurini, J. M., Kravitzs, S.R...Vanore, J.V. (2006). Diabetic Foot Disorders A Clinical Practice Giudelines. The Journal of Foot \& Ankle Surgery.45, 5, an official Publication of the AmericanCollage of Foot and Ankle Surgeons

Frykberk, R.G., Armstrong,. D.G., Giurini, J., Edwards, A., Kravette, M., Kravitz, S., Ross, C., Stavosky, J., Stuck, R., Vanore, J. (2000). Diabetic Foot Disorders : A Clinical Practice Guideline. Journal of Foot \& Ankle Surgery, 39:S1-S60.

Heitzman, J., (2010). Foot Care for Patient with Diabetes, Topics in Geriatric Rehabilitation. Vol 25. No.3. Wolter Kluwer Health. Lippincott Williams \& Wilkins

Kemenkes. Riset Kesehatan Dasar: Riskesdas 2013. Jakarta: Badan Penelitian dan Pengembangan Kesehatan Kementrian Kesehatan RI. 
Muliawan, M., Semadi, N., Yasa, K.P. (2007). Pola Kuman dan Korelasi Klinis Ulkus Kaki Diabetikum di RSUP Sanglah Denpasar. Tesis. Denpasar: Universitas Udayana.

Notoatmodjo, Soekidjo. (2010). Promosi Kesehatan: Teori dan Aplikasi. Jakarta, Rineka Cipta

Perkumpulan Endorin Indonesia. (2011). Pedoman penatalaksanaan kaki diabetik. Jakarta: PB. PERKENI

Purwanti, OS. 2013. Hubungan Faktor Risiko Neuropati Dengan Kejadian Ulkus Kaki Pada Pasien Diabetes Mellitus Di Rsud Moewardi Surakarta. Prosiding Seminar Ilmiah Nasional Kesehatan, ISSN: 2338-2694.

Registered Nurses' Association of Ontario. (2011). Reducing Foot Complication For people with Diabetes. Nursing Best Practice Guideline Shaping the Future of Nursing, March. Toronto,Ontario

Riset Kesehatan Dasar (Riskesdas). (2013). Laporan Badan Penelitian dan Pengembangan Kesehatan Departemen Kesehatan, Republik Indonesia.

Silbernagl, S \& Lang,F. (2007). Teks \& Atlas berwarna Patofisiologi. Jakarta: EGC

Smeltzer, S. \& Bare, B. (2006). Brunner \& Suddarth's Textbook of MedicalSurgical Nursing, $11^{\text {th }}$ ed., Philadelphia : Lippincott Williams \& Wilkins.

Van Baal, J.G. 2004. Surgical treatment of the Infected Diabetic Foot. Clinical Infectious Diseases, 39: S 123-8. 